\title{
Correlates Of Turnover Intention Among Rescue 1122 Workers
}

\author{
Maryam Munawar \\ \& \\ Talat Sohail \\ Department of Applied Psychology \\ Lahore College for Women University, Lahore
}

\begin{abstract}
The aim of this research was to explore the correlates of Turnover Intention. The correlates included Organization-based Self-esteem (OBSE), Job Stress (JS), Emotional Intelligence (EI), and Health Risk Behaviour (HRB) among Rescue 1122 Workers. The study also aimed to explore Emotional Intelligence (EI) as a predictor of Turnover Intention (TI); Organizationbased Self-esteem (OBSE), Job Stress (JS) and Health Risk Behaviour (HRB) among Rescue 1122 Workers. The sample of the study consisted of 200 male Rescue 1122 Workers of Lahore city. Systematic Random Sampling was employed to gather data from participants. Correlational Research Design was used. The major tools of this study included Turnover Intention Scale, Organization based Self-esteem Scale, The Subjective Job Stress Scale, Emotional Intelligence Scale and Health Risk Behaviour Questionnaire. These above mentioned tools were used after taking consent from the participants. Correlation and Regression Analysis were applied on the data. The results showed that there was significant positive relationship between Turnover Intention and Job Stress. Furthermore there was significant negative relationship between Turnover Intention and OBSE. Moreover Emotional Intelligence (EI) was a significant predictor of OBSE, Job Stress (JS), and Health Risk Behaviour (HRB).
\end{abstract}

Keywords: Turnover Intention, Rescue 1122 Workers, Organization Based Self-Esteem, Job Stress, Emotional Intelligence, Health Risk Behaviour.

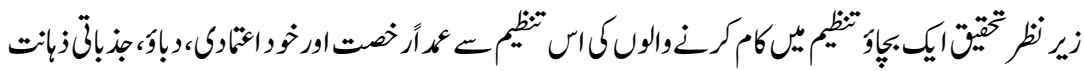

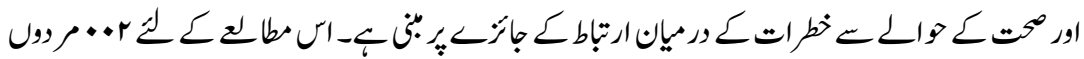

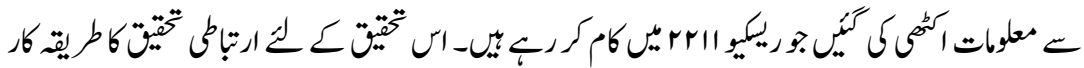

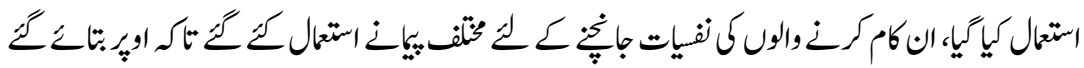




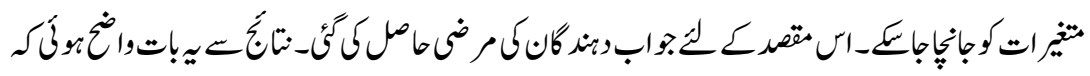

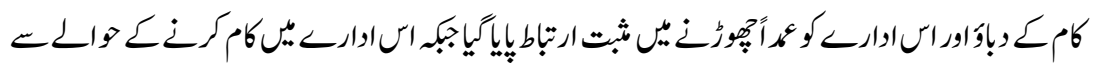

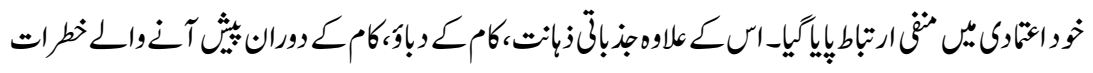

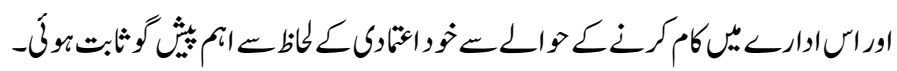

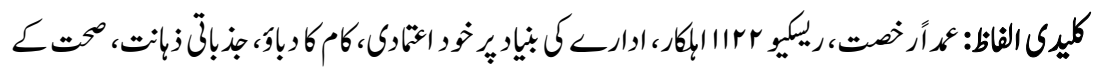

$$
\begin{aligned}
& \text { واسـات }
\end{aligned}
$$

The basic role of Rescue Workers in community is to provide protection not only to humans but also to environment and property. Their major roles in community include: providing assistance in daily emergencies which may include road side accidents, fires and explosions, rescuing people in natural calamities such as storms, earthquakes, floods and eruptions due to volcanoes, Rescue Workers have to provide protection to the community if there is some kind of industrial accident e.g., explosion of some dangerous and harmful materials in nuclear or in mining areas, Rescue Workers are required if there is some accident during transportation such as if there are railway accidents or car or plane crashes, Rescue Workers are required when there are serious criminal or terrorist attacks involving atomic bomb attacks or massive shootings, Rescue Workers are called for help if there are negative public events such as chaos during concerts, or sport events ( Hauke et al., 2011).All of the above duties are full of risk and they place Rescue Workers under great stress and may increase their Turnover Intention.

Turnover Intentions can be defined as "Conscious and deliberate wilfulness to leave the organization." Further they define Turnover Intention as "the last in a sequence of withdrawal cognitions, a set to which thinking of quitting and intent to search for alternative employment also belong" (Tett and Meyer 1993, p.262). Turnover of employees is a complex process. A research was conducted by Takase in 2010, the purpose of the research was understand the concept of Turnover Intention.The results of the study revealed that Turnover Intention is a process that has many stages including the quitting of job by employees by their own and leaving their recent job. In order to reduce Turnover nurse managers' should consider the reasons of nurses' Turnover.

Turnover Intentions can further be defined as willingly searching for other jobs in other organizations (Tett and Meyer 1993 as cited in Samad, 2006). There can be different reasons of quitting one's job. A study was carried out on hotel employees to understand the factors contributing towards turnover and what mangers can do 
to reduce it. The results revealed that more than eighty percent of employees quit their job to enhance and improve their career and seventy percent of employees' leave their job due to offer from other hotels (Yang, Wan, \& Fu, 2012).Turnover of employees can decrease the efficiency of the organizations (Smith \& Brough, 2003 as cited in Khan \& Anis-ul-Haque, 2009).

Turnover is a problem faced by many organizations which is a serious threat to the existence of an organization. Steps should be taken to identify causes of Turnover Intention and measures should be taken to minimize it.

Organization based Self-esteem (OBSE) is defined as the extent to which a worker believes himself to be able, important, and valuable as the member of the organization (Pierce \& Gardner, 2004). The workers with high levels of selfesteem consider them as 'valuable' in their workplace (Alam, 2009 as cited in Ibrahim, Zulkafli, \& Shah, 2014). Past findings have revealed that a person's self esteem that is developed because of his work and organizational context results in playing a remarkable role in formulating the workers' motivation behaviors and outlook associated with work. The findings revealed that an employee's worth in organization as indicated by the organization along with situations that promote success at organization predicted OBSE (Pierce \& Gardner 2004).

OBSE shows that how a person perceives his worth in an organization. Hence the workers who are confident and have high levels of self-efficacy in the organization as well as in other circumstances concurrently create a high level of self-esteem (Pierce, Gardner, Cummings, \& Randall, 1989).Literature search has shown that individuals who have high levels of self-esteem are more motivated towards their work and also have high levels of intrinsic motivation (Hui \& Lee, 2000).

The individuals who have high levels of OBSE show self- satisfaction from their work, have low rates of role stress and they are contended with their job roles within their organization. A study was carried on sales managers and advertising managers to find out the relationship between Role stress, self esteem and job satisfaction. The results showed that role stress had negative association with job satisfaction among the two groups whereas High self esteem that is high OBSE lowered down the role stress of the managers therefore indirectly affecting job satisfaction (Howell, Bellenger, \& Wilcox, 1987).

Employee Job Stress can be defined as "Job Stress is a relation between the individual and his environment of the workplace, as judged by the individual as demanding, strenuous and tough or beyond his assets, and causing danger to his 
own health" (Dewe \& Guest 1990 as cited in Cheng, 2009). Literature search has revealed that workers in organizations are at risk of both physiological or psychological deviations from normal daily functioning because of different situations that occur daily in their workplace. These deviations result from hindrances in achieving organizational goals, or demands causing important but indistinct results. As a result, the researchers have defined Job Stress as deviation from typical physiological or psychological routine that is caused by stress in the employee's environment (Beehr and Newman (1978), Cooper and Marshall (1976), Ivancevichand Matteson (1980), Katz and Kahn (1978), and Schuler (1980) as cited in Parker \& Decotiis, 1983).

Literature search has shown that $41 \%$ of people reported that workload was the principal source of Job Stress. A research was conducted on air traffic controllers to explore the relationship between Turnover Intention and Job Stress. The results revealed that the basic factor that affected Turnover Intention among air traffic controllers was heavy workload (Jou, Kuo, \& Tang, 2013).

Literature search has indicated that if employees feel stress of high level it may lead to annoyance, worry, anxiety, anxiety and sadness (Cartwright \& Cooper 2002; Martin 2005 as cited in Coetzee \& Villiers. 2010). Literature search has given evidence that the stress of work when calculated by work stress models of effort-reward imbalance, or by job strain the results showed that stress from work or Job Stress enhances the risks of psychosomatic, cardiovascular and mental disorders (Angerer \& Muller 2015).

Job Stress creates negative impacts on workers' health. A research was conducted on nurses in order to find out the influence of Job Stress. The results showed that Job Stress is a significant health risk factor for nurses (Trivellas, Reklitis, \& Platis 2013).

Emotional intelligence (EI) construct has been introduced by Salovey and Mayer in 1990 (Salovey \& Mayer, 1990). According to them EI refers to one's aptitude to be sensitive of one's own and other's emotions and feelings, to discriminate between them and to utilize this knowledge to direct one's own thoughts and actions.

Employees with high Emotional Intelligence show less Turnover Intention because EI helps workers to manage and control their emotions in a better way. Employees who have high levels of EI are more competent and can deal in a positive way in an emotional situation because they know their emotional states in a better way and can build up ways to better deal with their negative states of 
emotions. EI can be very useful to deal with emotional situations in the workplace (Krishnakumar, 2008 as cited in Bande, Fernandez-Ferrin, Jose, Varela, \& Jaramillo, 2014).

According to previous researches it is revealed that there is a negative relationship between Turnover Intention and Emotional Intelligence that is workers with high Emotional Intelligence show less Turnover Intention (Carmeli, 2003 as cited in Balogun \& Olowodunoye, 2012).

Health Risk behavior can be defined as any activity undertaken by individuals which raises the possibility of injury and illness (Steptoe \& Wardle, 2004 as cited in Baban \& Craciun, 2007).

Rescue Workers are specifically exposed to high risk environments during their duties. Every day they take a lot of calls that ask them for help and while carrying out their duties the workers are at a risk of a number of job related injuries and even fatalities (Houser, Jackson, Bartis, \& Peterson 2004). In a study conducted on employee Job Stress, workplace injury and illness, job dissatisfaction and Turnover Intention same information was revealed. This study was conducted on nurses and health care professionals. The objective of the study was to explore the relationship between injuries at workplace and perceptions of workplace safety and how the risk factors at workplace are related to doctors' overall health and their commitment to their job. The results indicated that there is a relationship between injuries at workplace and doctors' and nurses' poor perception of safety environment and that poor perceptions of workplace safety environment moderately affects the relationship between injuries at workplace and three variables that are job dissatisfaction, Job Stress and Turnover Intention. The conclusion of the study was that health care managers should take measures to improve the working conditions so that safety environment may change and there will be less Job Stress and Turnover Intention among them (McCaughey, DelliFraine, McGha, \& Bruning 2013).

The objective of each organisation is to make high yield, profit and deliver good quality services. These aims can only be achieved with worker's hard work and assistance. Workers are accountable for the accomplishment of organisation's objectives but when these workers are discerning of quitting or leaving (i.e., Turnover Intention) their jobs and the organisation, the goals of the organisation are not attained. Turnover intention may results in employees' turnover (i.e., loss of employee) which then results in a negative impact on the organizational yield, output, and efficiency (Balogun \& Olowodunoye, 2012). 
There is no place more suitable to study Turnover Intention then the emergency services this is because Rescue Workers have to face considerable number of job stressors and upsetting incidents every day that may lead to reduced level of job performance further leading to poor performance increasing Job Stress of the Workers with an intention to quit the job hence enhancing Turnover Intention.

\section{Hypotheses}

- It is hypothesized that there is relationship between Turnover Intention and Organization-based Self-esteem in Rescue 1122 Workers.

- It is hypothesized that there is relationship between Turnover Intention and Job Stress in Rescue 1122 Workers.

- It is hypothesized that there is relationship between Turnover Intention and Emotional Intelligence in Rescue 1122 Workers.

- It is hypothesized that there is relationship between Turnover Intention and Health Risk Behaviors in Rescue 1122 Workers.

- It is hypothesized that Emotional Intelligence is a predictor of Job Stress, Organization based Self-esteem, Turnover Intention and Health Risk Behavior in Rescue 1122 Workers.

\section{Method}

\section{Research Approach}

A quantitative approach was used.

\section{Research Design}

Correlational research design was used.

\section{Population}

All registered Rescue Workers of Lahore consisting of 870 total Rescue Workers.

\section{Sampling Strategy}

Systematic Random Sampling was used for sample selection. A list of all registered Rescue 1122 workers of Lahore city was obtained, total number of Rescue Workers was 870 and out of the list every $4^{\text {th }}$ individual was chosen from the list until we reached 200 individuals. The sample consisted of 200 male Rescue 1122 Workers placed in Lahore city. 


\section{Inclusion Criteria}

While taking sample the following criteria were kept in mind: The sample was collected from urban area. The sample was taken from Lahore. Only Rescue 1122 workers were included. Workers with minimum two years' experience were included.

\section{Exclusion Criteria}

The exclusion criteria of the study are as follows: The sample was not taken from rural area. Workers with less than two years' experience were excluded.

\section{Operational Definitions of Variables}

Turnover Intention. Turnover Intention is defined as a person's expected possibility that he would depart an institute in upcoming time (Brough \& Rachael, 2004). Turnover intentions are recognized as direct precursor of turnover behavior (Mobley, Horner, \& Holligsworth, 1978; Tett \& Meyer, 1993 as cited in Khan, \& Anis-ul-Haque, 2009).

Organization-based Self-Esteem (OBSE). OBSE is explained as a worker's self-evaluated value which a worker perceives of himself as being a part of an institute (Pierce, Gardner, Cummings, and Dunham 1989 as cited in Pierce, \& Gardner 2004).

Job Stress. It is defined as the factors related to job which are perceived by workers to have influence on the worker's health and well-being (Hurrell, Nelson, and Simmons, 1998 as cited in Rauf \& Farooq, 2014).

Emotional Intelligence. EI includes evaluation of emotions in a person's himself and in other individuals, emotions generation, their regulation in a person himself and in other individuals, and using emotions in resolving difficulties (Schutte, Malouff, \& Bhullar, 2009).

Health Risk Behavior (HRB). Health-risk behavior is defined as any action carried out by persons which has power that raises danger of illness or damage (Steptoe \& Wardle, 2004 as cited in in Baban \& Craciun, 2007).

\section{Variables and Measures}

Measures that were used in this study:

- Turnover Intention Scale by (Cammann, Fichman, Jenkines, \& Klesh, 1979). 
- Organization-based Self-esteem Scale (OBSE) by (Pierce et al., 1989).

- The Subjective Job Stress Scale (SJSS), (Motowidlo, Packard, \& Manning, 1986), (Urdu Translation by Kalida Rauf \& Asim Farooq, 2014).

- Emotional Intelligence Scale by (Schutte et al., 1998).

- Health Risk Behavior Questionnaire adapted from a guide for employers, HSE (2013) booklet HS(G)165.

\section{Instruments and Tools}

Turnover Intention Scale. Turnover Intentions were evaluated by 3-item key of employees' intention to quit their job developed by (Cammann, Fichman, Jenkines \& Klesh 1979). The first item included likert scale that is of 7 points ranging from Not at all likely (1) to Extremely Likely (7) and the other two items included response scale that was also of 7 points varying from Strongly Disagree (1) to Strongly Agree(7). The reliability of the scale was 0.78.

Organization based Self- Esteem Scale. The scale was developed by (Pierce et al., 1989) it was comprised of ten items. The Scale ranged from (e.g., 1: strongly disagree to 5: strongly agree). Higher scores indicate higher OBSE. The reliability of the scale was 0.91 .

The Subjective Job Stress Scale (SJSS). The SJSS consisted of four items. It was developed by (Motowidlo, Packard, \& Manning, 1986), its Urdu Translation was done by (Khalida Rauf \& Asim Farooq, 2014) .Two items (item \# 2 \& 4) were reverse scored. It was a likert- type scale, which ranged from strongly disagree (1) to strongly agree (5). The greater the scores the greater will be the Job Stress. The reliability of the scale was 0.82 .

Emotional Intelligence Scale. This scale was developed by (Schutte et al., 1998). It consisted of 33 items. It was a Likert type scale which varied from 1(strongly disagree) to 5 (strongly agree). The items of the scale were separated in to four sub-areas such as: managing emotions of other people, using emotions, managing own emotions, and perceiving of emotions. Three items were reverse coded 5, 28 and 33 . The reliability of the scale was 0.90 .

Health Risk Behavior Questionnaire. The Health Risk Behavior is a ten item questionnaire that was adapted from a guide for employers, HSE (2013) booklet $\mathrm{HS}(\mathrm{G}) 165$. It consisted of ten items. It scores ranged from 1 (Never) to 5 (Always). Higher score indicate high risk. The reliability of scale was adequate as it was 0.58 . 


\section{Results}

Table: 1

Table showing demographics

\begin{tabular}{|c|c|c|}
\hline Demographics & $\mathbf{F}$ & $\%$ \\
\hline \multicolumn{3}{|l|}{ Age } \\
\hline $20-35$ & 185 & 91.1 \\
\hline $46-50$ & 15 & 7.4 \\
\hline \multicolumn{3}{|l|}{ Education } \\
\hline Lower education & 79 & 38.9 \\
\hline Higher education & 121 & 59.6 \\
\hline \multicolumn{3}{|l|}{ Marital status } \\
\hline Married & 63 & 31.0 \\
\hline Unmarried & 137 & 67.5 \\
\hline \multicolumn{3}{|l|}{ Occupation of wife } \\
\hline Housewife & 123 & 60.6 \\
\hline Working & 13 & 6.4 \\
\hline \multicolumn{3}{|l|}{ Number of children } \\
\hline $0-3$ & 175 & 86.2 \\
\hline $4-7$ & 24 & 11.8 \\
\hline \multicolumn{3}{|l|}{ Family system } \\
\hline Nuclear & 43 & 21.2 \\
\hline Joint & 157 & 77.3 \\
\hline \multicolumn{3}{|c|}{ Number of family members } \\
\hline Less than nine & 173 & 85.2 \\
\hline More than nine & 27 & 13.3 \\
\hline \multicolumn{3}{|l|}{ Monthly income } \\
\hline $10,000-30,000$ & 179 & 88.2 \\
\hline $31,000-50,000$ & 21 & 10.3 \\
\hline \multicolumn{3}{|c|}{ Total income of all family members } \\
\hline $20,000-60,000$ & 151 & 74.4 \\
\hline $61,000-1,00,000$ & 49 & 24.1 \\
\hline
\end{tabular}

Note. $\mathrm{F}=$ Frequency, $\mathrm{P}=$ Percentage.

Table showed Frequencies and Percentages of the demographic variables. The demographic variables included Age, Education, Marital status of the employee, Occupation of wife, Number of Children, Family system, Number of Family members, Monthly Income and Total income of all family members.

The table showed that $91.1 \%$ of Rescue Workers fell in the age range of 20-35 and $7.4 \%$ fell in the age range of 46-50. $38.9 \%$ had low education that is below graduation and $59.6 \%$ had achieved higher education. $31.0 \%$ were married and $67.5 \%$ were unmarried, among married Rescue Workers $60.6 \%$ Rescue Workers' 
wives were non working and $6.4 \%$ Workers' wives were working women. Other demographics revealed that $86.2 \%$ had children less than three and $11.8 \%$ had more than three children. $21.2 \%$ had nuclear family system and $77.3 \%$ had joint family system. $85.2 \%$ had family members less than 9 and $13.3 \%$ had family members above nine. $88.2 \%$ had individual income between Rs 10,000-50,000 and $10.3 \%$ had individual income between $31,000-50,000$ as far as total income of all family members is concerned $74.4 \%$ had total income between Rs 20,00060,000 and $24.1 \%$ had family income between Rs 61,000-100,000.

Table: 2

Table showing relationship between turnover intention, organization based self-esteem, job stress, emotional intelligence and health risk behaviour among rescue 1122 workers $(\mathrm{N}=\mathbf{2 0 0})$

\begin{tabular}{|l|c|c|c|c|c|}
\hline Variables & $\mathbf{1}$ & $\mathbf{2}$ & $\mathbf{3}$ & $\mathbf{4}$ & $\mathbf{5}$ \\
\hline 1. TI & - & $-.15^{*}$ & $.32^{* *}$ & 0.05 & -.011 \\
\hline 2. OBSE & - & - & .01 & $.37^{* *}$ & $.30^{* *}$ \\
\hline 3. JS & - & - & - & $.25^{* *}$ & $.43^{* *}$ \\
\hline 4. EI & - & - & - & - & $.29^{* *}$ \\
\hline 5. HRB & - & - & - & - & - \\
\hline
\end{tabular}

Note. ${ }^{*} \mathrm{p}<0.05,{ }^{* *} \mathrm{p}<0.01$ TI: Turnover Intention, OBSE: Organization Based Self-esteem, JS: Job Stress, EI: Emotional Intelligence and HRB: Health Risk Behavior.

Pearson product moment correlation was run to find out the relation in Turnover Intention, Organization based Self-esteem, Job Stress, Emotional Intelligence and Health Risk Behavior among Rescue 1122 Workers. The results revealed that there was significant negative relationship between Turnover Intention and Organization-based Self-esteem $\left(\mathrm{r}=-.15^{*}, p<0.05\right)$, which proved our hypothesis. Moreover there was a significant positive correlation between Turnover Intention and Job Stress $\left(\mathrm{r}=.32^{* *}, p<0.01\right)$, which proved our hypothesis. Similarly there was a significant positive relationship in Organizationbased Self-esteem and Emotional Intelligence $\left(\mathrm{r}=.37^{* *}, p<0.01\right)$ and Organization-based Self-esteem and Health Risk Behavior and $(\mathrm{r}=.30 * * p<0.01)$, among Rescue 1122 Workers. Furthermore significant positive relationship was also found between Job Stress, Emotional Intelligence $\left(\mathrm{r}=.25^{* *}, p<0.01\right)$ and Job Stress and Health Risk Behavior $(\mathrm{r}=.43 * * p<0.01)$, There was significant positive relationship in Emotional Intelligence and Health Risk Behavior $(r=.29 * *$, $p<0.01$ ) among Rescue 1122 workers. There was no significant relationship between Turnover Intention and Emotional Intelligence $(r=0.05, \mathrm{p}>0.05)$ which rejected our hypothesis, similarly there was no significant relationship between TI and HRB $(r=-.01, p>.05)$ hence our hypothesis was rejected. 
Table: 3

Table showing linear regression between emotional intelligence (EI), turnover intention (TI) job stress (JS) organization based self-esteem (OBSE) and health risk behaviour (HRB)

\begin{tabular}{|l|c|c|c|c|c|c|c|c|}
\hline \multicolumn{7}{|c|}{ Dependent Variables TI, OBSE, JS, HRB } \\
\hline Predictor(EI) & B & SE & Beta & T & P & F & R Square & R \\
\hline EI(TI) & .01 & .01 & .05 & 00.76 & 0.45 & 0.59 & 0.00 & 0.05 \\
\hline EI(OBSE) & .19 & .03 & .37 & 5.50 & 0.00 & 31.32 & .13 & .37 \\
\hline EI(JS) & .05 & .01 & .26 & 3.7 & 0.00 & 13.97 & .06 & .26 \\
\hline EI(HRB) & .19 & .04 & .29 & 4.41 & 0.00 & 19.43 & 0.09 & .29 \\
\hline
\end{tabular}

Note. ${ }^{*} \mathrm{p}<0.05, * * \mathrm{p}<0.01$ TI: Turnover Intention, OBSE: Organization based Self-esteem, JS: Job Stress, EI: Emotional Intelligence and HRB: Health Risk Behaviour.

Linear regression was run to find out whether EI was a predictor of TI and the results showed that EI was not a significant predictor of TI as $(p>0.05, \mathrm{p}=0.45)$, which rejected our hypothesis. Moreover it was found out whether that EI was a significant predictor of OBSE and the results showed that EI was a significant predictor of OBSE as $(p<0.01, \mathrm{p}=0.00)$ which proved our hypothesis. Then it was revealed that EI is a significant predictor of JS $(p<0.01, \mathrm{p}=0.00$. Lastly it was shown that EI was a significant predictor of $\operatorname{HRB}(p<0.01, \mathrm{p}=0.00)$.

\section{Discussion}

The aim of the present study was to explore the correlates of Turnover Intention (TI) among Rescue 1122 Workers; the correlates included Organization based Self-esteem (OBSE), Job Stress, Emotional Intelligence and Health Risk Behaviour.

There is a rich source of literature on the above listed variables in western culture, but in Pakistan these variables have not been studied previously. Even in western culture there are various researches on Turnover Intention, OBSE and Job Stress these variables were not specifically studied with Rescue Workers.

Rescue services is a very tough job as Rescue Workers daily face a large number of stressors related to their job which put them under a great deal of stress e.g., they provide services when there is some natural calamity like earthquake and flood, whereas sometimes they have to provide help if there is some kind of emergency such as a building on fire, or there are some kind of atomic bomb explosions or chaos created in a public event. All these duties are full of risks and they place Rescue Workers under stress, when Rescue Workers face Job Stress their performance decreases which in turn lower down their self esteem regarding their organization and Turnover Intention increases leading them to quit their job. 
The present study was conducted to gain an insight of what are the basic or main factors that affect employee Turnover. It was hypothesized that there is relationship between Turnover Intention and OBSE and the findings revealed that there is a significant negative relationship between Turnover Intention and OBSE that is as a person's self esteem regarding his organization increases there is a decrease in Turnover Intention. Past findings have also shown that workers who consider themselves valuable for the organization have high self-esteem and they show a decrease in Turnover behaviour (Pierce \& Gardner, 2004).

Furthermore the findings of our study indicated that there is significant positive relationship between Job Stress and Turnover Intention among Rescue 1122 Workers. Literature search has also supported our findings, a study was carried out by Kuo, Jou and Lin in 2012 there sample consisted of air traffic controllers and their findings revealed that as Job Stress among workers increases their Turnover Intention increases as well.

According to Bio-psychosocial model the biological, psychological and social factors all play their relevant part in determining any outcome. In Rescue 1122 Workers Job Stress affects biological component i.e. physical health is affected Job Stress, their psychological health is also affected i.e., deviation from normal physical functioning which then affects the social functioning i.e., relations within the organization thereby reducing their social functioning and decreasing their self-esteem within the organization (OBSE), which results in lowering down their job performance which eventually enhances Turnover Intention among the employees. Therefore Job Stress affects the biological, psychological and social functioning of the Workers and all these factors play a significant role in enhancing Turnover Intention among Rescue Workers.

Moreover our findings showed that there is no significant relationship between Turnover Intention and Emotional Intelligence although previous researches have supported that there is a significant relationship between Turnover Intention and Emotional Intelligence. A previous research was carried out by Krishankumar in 2008 the sample consisted of 278 workers in the field of law and some of them were physicians and the results confirmed that workers with high EI show less turnover (TI). These findings were contrary to our research findings this is because the study was conducted in Pakistan where organizational culture is not well structured as in western countries. In Pakistan no one pays much attention to emotions and how to use them effectively during everyday routine duties in organizational working hours.

Our next hypothesis which was that there is significant relationship between Turnover Intention and Health Risk Behaviour was not supported by our findings. Although this hypothesis was supported by previous researches that there is relationship 
between Health Risk Behaviour and Turnover Intention as supported by a research done in 2013 by McCaughey, DelliFraine, McGhan and Bruning, the research was conducted on nurses and it was revealed that workplace injuries result in high turnover rates which is contrary to our findings because data was limited, otherwise in our sample of Rescue 1122 Workers one of the main reasons of quitting one's job can be risks associated with the everyday daily emergencies. According to sociocultural perspective in Pakistan a reason of employees not quitting their jobs even if risks are associated with their jobs can be the perception of Turnover behaviour, in Pakistan Turnover behaviour is not considered a favourable attitude so employees do not quit even if there is risk in their jobs. Secondly in Pakistan rates of job availability are very low which compels employees to continue their jobs no matter how much risk are associated with the jobs.

Regression analysis revealed that EI is not significant predictor of Turnover Intention (TI) although previous researches have shown that workers with high Emotional intelligence show less Turnover Intention as previously described in the research conducted by Krishnakumar which supported that Emotional Intelligence significantly predicted Turnover Intention that is as EI increases TI lowered down. Our hypothesis was rejected reason can be in Pakistani culture no one understands the value and importance of emotions.

Regression analysis further indicated that Emotional Intelligence is a significant predictor of Job Stress. Further it can be inferred that if a person has high Emotional Intelligence he has the ability to cope with stressful situations effectively and instead of falling apart he may show a positive attitude by effectively dealing with Job Stress. This is supported by a study done by Sy, Tram, O'Hara (2002) Nikolaou and Tsaousis (2002) whose findings revealed that greater the Emotional Intelligence lower will be the Job Stress among workers. But our findings are contradictory with previous researches as in Pakistan no one understands how to use emotions effectively to lower down Job Stress.

As far as it was hypothesized that Emotional intelligence is a significant predictor of OBSE the results confirmed the hypothesis that Emotional Intelligence significantly predicts OBSE, our hypothesis is supported by a research which was conducted by Varasteanu and Iftime in 2013 on school students that revealed that greater the Emotional intelligence greater will be self esteem of students.

Then our findings revealed that EI is a significant predictor of Health Risk behavior as a research was conducted by Weigand in 2007, according to this research the greater Emotional Intelligence of a worker greater will be his capability to avoid workplace injuries that is greater Emotional Intelligence lower will be the injuries, our findings are contradictory to previous researches, the reason can be that in Pakistan workers are not aware of how to use Emotional Intelligence to avoid workplace injuries. 


\section{Conclusions}

Our findings revealed that Job Stress enhances Turnover Intention among Rescue 1122 Workers which may have a detrimental effect on the emergency rescue services whereas OBSE has a negative relationship with Turnover Intention which is greater the OBSE lower will be Turnover Intention. Literature search has revealed that workers with high OBSE show less Turnover Intention. So in order to reduce Turnover among Rescue Workers the organization should take measures to enhance OBSE and reduce Job Stress among Workers.

\section{Limitations}

Firstly, conducting research in a limited time was very difficult. Due to shortage of time only 200 male Rescue Workers were included.

Secondly it was very difficult to collect data from Rescue 1122 workers as they were always on job duties which included handling emergencies, so due to their busy nature of job they showed less interest in participating in the research process.

\section{Recommendations}

In present research data was collected only from male Rescue Workers, female Rescue Workers were not a part of the research. In future female Rescue Workers shall also be included to make comparisons in rates of Turnover Intention among Rescue 1122 workers.

Furthermore by conducting further research various factors can be identified which may reduce Turnover Intention among workers.

\section{Implications}

The findings of the research can be used by organizations to lessen the Job Stress and to enhance the Organization based Self-esteem so that Turnover Intentions among workers may decline.

\section{References}

Angerer, P. \& Muller, A. (2015). Occupational Stress Management. International Encyclopaedia of the Social \& Behavioural Sciences, 2nd edition, vol.17, pp.147-152. 
Baban, A. \& Craciun, C. (2007). Changing Health-Risk Behaviours: A Review of Theory and Evidence-Based Interventions In Health Psychology. Journal of Evidence-Based Psychotherapies, vol.7:1, pp.45-67.

Balogun, A. G. \& Olowodunoye, S. A. (2012). Psychological Factors as Predictors of Turnover Intention among Employees of Post-Consolidation Banks in Nigeria, European Scientific Journal, vol.8:20, pp.81-95.

Bande, B., Fernandez-Ferrin, P., Varela, J.A. \& Jaramillo, F. (2014). Emotions and Salesperson Propensity to Leave: The Effects of Emotional Intelligence and Resilience. Industrial Marketing Management.

Brough, P. \& Frame, R. (2004). Predicting Police Job Satisfaction and Turnover Intentions: The Role of Social Support and Police Organizational Variables. New Zealand Journal of Psychology, vol.33:1, pp.8-16.

Cheng, C.H. (2009). The Relationship among Employee's Work Values, Job Stress. Parkway: Pro Quest LLC.

Coetzee, M. \& Villiers, M. D. (2010). Sources of Job Stress, Work Engagement and Career Orientations of Employees in a South African Financial Institution. Southern African Business Review, vol.14:1, pp.27- 58.

Hauke et al., (2011). Emergency Services: A Literature Review on Occupational Safety and Health Risks. Europe: European Agency for Safety and Health at Work (EU- OSHA).

Howell, R. D., Bellenger, D. N. \& Wilcox, J.B. (1987). Self-Esteem, Role Stress, and Job Satisfaction among Marketing Managers, Journal of Business Research 15, pp.71-84.

Houser, A. N., Jackson, B. A., Bartis, J. T. \& Peterson. D. J. (2004). Emergency Responder Injuries and Fatalities: An Analysis of Surveillance Data. USA: Rand Cooperation.

Hui, C. \& Lee, C. (2000). Moderating Effects of Organization-Based Self-Esteem on Organizational Uncertainty: Employee Response Relationships. Journnal of Management, vol.26:2, pp.215-232.

Ibrahim, H. I., Zulkafli, A. B. \& Shah, K. A. M. (2014). An Empirical Investigation of Organisation Based Self-Esteem and In-Role Performance across Diverse Occupations, International Journal of Research in Commerce \& management, vol.5:4, pp.65-69. 
Khan, M. A. \& Anis-ul-Haque, M. (2009). Interpersonal Conflict with Colleagues and Superiors and its Differential Impact on Job-Related Outcomes. The Journal of Humanities and Social Science, vol.17:1.

Krishnakumar, S. (2008). The Role of Emotional Intelligence and Job Emotional Requirements in Job Attitudes and Behaviour, ( $\mathrm{PhD}$ Dissertation), Virginia Polytechnic Institute and State University, Blacksburg, Virginia.

Kuo, C. W., Jou, R. C. \& Lin, S. W. (2012). Turnover Intention of Air Traffic Controllers in Taiwan: A Note, Journal of Air Transport Management, vol.25, pp.50-52.

Jou, R. C., Kuo, C. W. \& Tang, M. L. (2013). A Study of Job Stress and Turnover Tendency among Air Traffic Controllers: The Mediating Effects of Job Satisfaction. Transportation Research Part E: Logistics and Transportation Review, vol.57, pp.95-104.

McCaughey, D., DelliFraine, J.L., McGha, G. \& Bruning, N.S. (2013). The Negative Effects of Workplace Injury and Illness on Workplace Safety Climate Perceptions and Health Care Worker Outcomes. Safety Science vol.51, pp.138-147.

Parker, D. F. \& Decotiis, T. A. (1983). Organizational Determinants of Job Stress. Organizational Behaviour and Human Performance, vol.32, pp.160-177.

Pierce, J. L., Gardner, D. G., Cummings, L. L., \& Randall, B. (1989). Organization-Based Self-Esteem: Construct Definition Measurement, and Validation. The Academy of Management Journal, vol.32:3, pp.622-648.

Pierce, J. L. \& Gardner, D. G. (2004). Self-Esteem within the Work and Organizational Context: A Review of the Organization-Based Self-Esteem Literature. Journal of Management, vol.30:5, pp.591-622.

Rauf, K. \& Farooq, A. (2014). Translation and Adaptation of Subjective Job Stress Scale into Urdu, Pakistan Business Review, pp.177- 195.

Samad, S. (2006). The Contribution of Demographic Variables: Job Characteristics and Job Satisfaction on Turnover Intentions. Journal of International Management Studies, vol.1:1, pp.1-12.

Salovey, P. \& Mayer, J. D. (1990). Emotional Intelligence. New Haven: Baywood Publishing Company. 
Sy, T. Tram, S. \& Hara, L.A. (2006). Relation of Employee and Manager Emotional intelligence to Job Satisfaction and Performance. Journal of Vocational Behaviour, vol.68, pp.461-473.

Schutte, N.S., Malouff, J.M. \& Bhullar, N. (2009). The Assessing Emotions Scale. C. Stough, D. Saklofske \& J. Parker (Eds.), The Assessment of Emotional Intelligence. New York: Springer Publishing, pp.119-135.

Takase. M. (2010). A Concept Analysis of Turnover Intention: Implications for Nursing Management. Collegian, vol.17, pp.3-12.

Tett, R. P. \& Meyer, J. P. (1993). Job Satisfaction, Organizational Commitment, Turnover Intention and Turnover: Path Analyses Based on Meta-Analytic Findings. Personnel Psychology, pp.259-293.

Trivellas, P., Reklitis, P. \& Platis, C. (2013). The Effect of Job Related Stress on Employees' Satisfaction: A Survey in Health Care Procedia - Social an Behavioural Sciences, vol.73, pp.718-726.

Varașteanu, C. M. \& Iftime, A. (2013). The Role of the Self-Esteem, Emotional Intelligence, Performance Triad in Obtaining School Satisfaction, Procedia - Social and Behavioural Sciences, vol.93, pp.1830-1834.

Wiegand, D.M. (2007). Exploring the Role of Emotional Intelligence in Behaviour-Based Safety Coaching. Journal of Safety Research, vol.38, pp.391-398.

Yang, J., Wan, C. \& Fu, Y., (2012). Qualitative Examination of Employee Turnover and Retention Strategies in International Tourist Hotels in Taiwan. International Journal of Hospitality Management, vol.31, pp.837848.

Miss Maryam Munawar is Student in the Department of Applied Psychology, Lahore College for Women University, Lahore.

Prof. Talat Sohail is Head of the Department of Applied Psychology, Lahore College for Women University, Lahore. 